www.volsu.ru

DOI: https://doi.org/10.15688/jvolsu3.2017.2.14

UDC 33.338 .2

LBC 65.054

\title{
THE PROBLEMS OF BUDGET FUNDING OF HIGHER EDUCATION INSTITUTIONS: ANALYSIS AND IMPROVEMENT
}

\author{
Viktor V. Kovelskiy \\ Samara National Research University named after S.P. Korolev, Samara, Russian Federation \\ Kseniya A. Sidorenkova \\ Samara National Research University named after S.P. Korolev, Samara, Russian Federation
}

\begin{abstract}
The main problem of financing higher education institutions is the lack of public funds allocated from the budget. At this stage of the development of budgetary financing for universities, we see a gradual finance withdrawals happening on the basis of estimates, and the transition to "efficient" financing. Such financing has its supporters and opponents. The main argument "for" performance-oriented budgeting is that this method of obtaining funds stimulates more rational use of them. The arguments "against" such financing are also important: such budgeting leads to "work for the indicator" without a significant impact to the internal forces of the university, and the indicators on the basis of which the university finances, in no way make it possible to assess the real quality of the work. For example, the indicator of the number of trained specialists does not reflect the real quality of education in the university. Immediate results of the activities of higher education institutions are the provision of educational or other services of a certain quality or volume. There are several mechanisms that allow to evaluate the effectiveness of the university's activities used abroad. The authors of this article propose to evaluate the effectiveness of the university in the context of several areas of its activities: education, innovation and scientific research. On the basis of received indicators the higher education institutions will be distributed by "groups", on which the final amount of funding depends. Such system of financing and the developed formulas for calculation of financial assets volumes are approbated on the example of the Samara National Research University, that allowed to identify the advantages and disadvantages of the presented calculation method.
\end{abstract} funding.

Key words: efficiency, financing, budgeting, performance indicators, higher education institution, per capita

УДК 33.338 .2

ББК 65.054

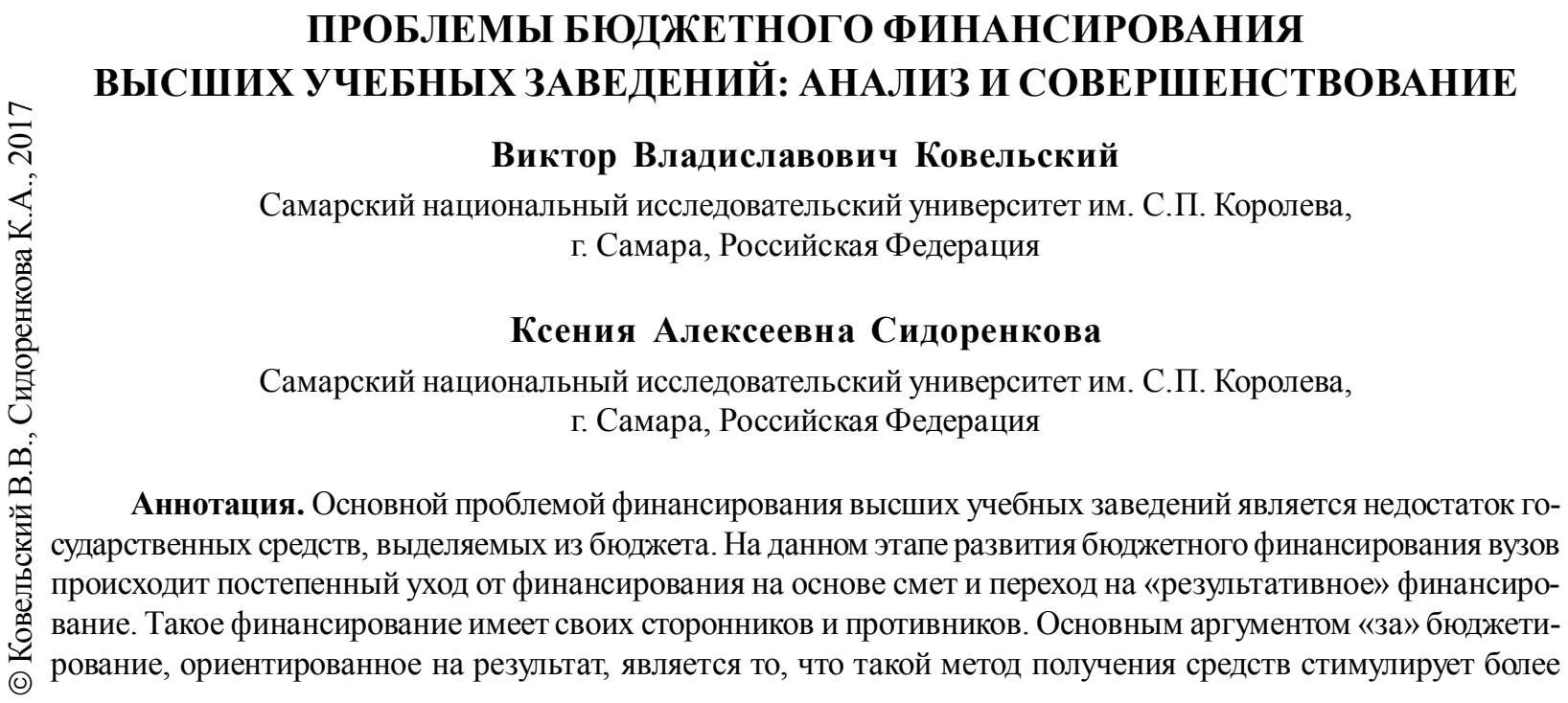


рациональное их использование. Не менее вескими являются аргументы «против» такого финансирования: такое бюджетирование ведет к «работе на показатель» без существенной отдачи внутренних сил университета, а также показатели, на основе которых происходит финансирование вуза, никоим образом не позволяют оценить реальное качество работы. Например, показатель количества подготовленных специалистов не отражает реальное качество обучения в вузе. Непосредственными результатами деятельности высших учебных заведений является предоставление образовательных или иных услуг определенного качества или объема. Существует несколько механизмов, позволяющих оценивать результативность деятельности вуза, используемых за рубежом. Предлагается оценивать результативность вуза в разрезе нескольких направлений его деятельности: образование, инновации и научные исследования. На основе полученных показателей будет производиться распределение вузов по «группам», от которых зависит окончательный объем финансирования. Приведенная система финансирования и разработанные формулы для расчета объемов финансовых средств апробированы на примере Самарского национального исследовательского университета им. С.П. Королева, что позволило выявить достоинства и недостатки представленного метода расчета.

Ключевые слова: эффективность, финансирование, бюджетирование, показатели эффективности деятельности, высшее учебное заведение, нормативно-подушевое финансирование.

В связи с усилением конкуренции на российском и международном рынке образовательных услуг, все увеличивающимся ростом информационной открытости вузов, усилением роли стратегического планирования и бюджетирования ориентированных на результаты вузов, показатели играют все большую роль в их деятельности.

В научно-публицистической литературе предлагается подразделять показатели результатов деятельности вузов, которые чаще всего представлены в их «road maps» или оперативных документах, на показатели конечных и непосредственных результатов [8]. Непосредственными результатами деятельности вуза является предоставление образовательных или иных услуг определенного качества и объема. Показатели непосредственных результатов деятельности включают в себя количество студентов, которые обучены по определенным образовательным программам, процент выпускников, устроившихся по специальности, и т. д. Конечным результатом является социально-экономический эффект от предоставленных вузом услуг для их получателей, например, карьерный рост выпускников по специальности, доходы выпускников, удовлетворенность работодателей качеством подготовки специалистов .

Несмотря на то что использование показателей результативности при финансировании высшего образования становится все более распространенным, продолжаются споры «за» и «против» использования этих показателей при вынесении решения об объеме финансирования. Специалисты, придерживающиеся положи- тельной точки зрения по данному вопросу, высказывают следующие аргументы «за»:

- взаимосвязь финансирования и результатов стимулирует более рациональное использование ресурсов получателями бюджетных средств;

- бюджетирование, ориентированное на результаты, позволяет оценить эффективность государственной политики в определенной области, распределять ответственность между различными уровнями власти и другими организациями, сравнивать работу различных организаций;

- использование показателей результативности даже без прямой увязки с финансированием стимулирует организации к улучшению их работы, повышает их открытость и подотчетность обществу.

Одновременно с аргументами «за» высказываются серьезные доводы и против использования бюджетирования, ориентированного на результаты, - или, по крайней мере, абсолютизации этого механизма финансирования в приложении к высшему образованию. Главными аргументами противников расширения использования показателей результативности являются следующие [2]:

- использование бюджетирования, ориентированного на результат (БОР), неуклонно ведет к феномену «работы на показатель» и создает стимулы к искажению данных у получателей бюджетных средств. Отдельная проблема состоит в интерпретации полученных значений показателей;

- те показатели, которые относительно легко измеряются, как правило, не являются 
показателями конечного результата, и не отражают реальное качество работы вуза. Например, активно используемый показатель количества подготовленных специалистов никак не отражает качества образования. При этом стоит признать, что измерить результаты научной деятельности вузов в целом проще, чем образовательной (хотя и здесь есть проблемы интерпретации результатов и возможности работы на показатель). Поэтому часть противников использования БОР для финансирования учебной деятельности признают применимость этого метода для финансирования вузов в области науки;

- в сфере высшего образования не наблюдается прямой связи между качеством обучения (и исследовательской деятельности) и объемами финансирования - по крайней мере, в краткосрочном и среднесрочном периодах.

Основные сложности использования методов финансирования на основе показателей результативности в системе высшего образования связаны именно с обоснованием и подтверждением показателей результатов деятельности вузов. В основном в качестве наиболее значимого показателя результата деятельности вуза используется численность студентов, закончивших вуз в установленные сроки. Но, по мнению председателя Российского студенческого союза Артема Хромова, данный показатель не отражает качества полученного образования [7]. Если финансирование будет ориентировано на количество студентов, получивших дипломы, то у вузов появляется стимул к выдаче наибольшего количества дипломов в ущерб качеству образования. Для решения этой проблемы, отмеченной как исследователями, так и руководителями органов, ответственных за развитие и финансирование образования в разных странах, предпринимаются попытки создания интегрального показателя, который бы отражал качество образования, или набора таких показателей. Однако до сих пор не удалось создать набор таких показателей, которые отвечали бы критериям точности, адекватности, неманипулируемости и относительной дешевизны расчета.

Проведенный анализ практики бюджетного финансирования вузов в зарубежных странах позволяет обобщить национальное многообразие механизмов финансирования к шести основным типам:

1) бюджетирование по результатам обсуждения проекта представленного вузом бюджета уполномоченными государственными органами и вузами;

2) бюджетирование на основе оценивания расходов вузов в предшествовавшем периоде;

3) бюджетирование, основанное на расчетном финансировании вузов, когда государственные органы принимают решение на основе расчетов, опирающихся на показатели затрат или результатов деятельности вузов;

4) бюджетирование на основе контрактов между государством и вузами о предоставлении образовательных услуг в соответствии со стратегическими целями страны или вуза;

5) заключение контрактов между государственными органами и вузами, которые содержат целевые показатели выпуска определенного количества специалистов различных специальностей для принятия решения о размере финансирования;

6) целевое финансирование специфических исследовательских и образовательных проектов вуза.

В таблице ниже представлены данные об использовании конкретных вышеупомянутых механизмов в странах ЕС (см. табл. 1).

Проанализировав данные таблицы 1 , можно заметить, что в большинстве стран ЕС используется расчетный подход (формульное финансирование) к принятию решения о размере финансирования вуза. Данный подход является преимущественным в финансировании высшего образования таких стран, как Эстония, Бельгия, Латвия, Литва, Венгрия, Нидерланды, Швеция, Великобритания и Лихтенштейн.

Большинство стран вполне успешно используют комбинации из нескольких механизмов.

Во многих развитых странах в основе финансирования образования лежит метод нормативно-подушевого финансирования, который основывается на расчете норматива затрат на обучение одного студента и численности студентов, либо каких-то других коли- 
Способы бюджетного финансирования высшего образования в странах ЕC в 2013-2014 гг.

\begin{tabular}{|c|c|c|c|c|c|c|}
\hline Страны & $\begin{array}{c}\text { Переговор- } \\
\text { ный подход } \\
\text { на базе } \\
\text { предвари- } \\
\text { тельного } \\
\text { проекта } \\
\text { бюджета, } \\
\text { предложен- } \\
\text { ного вузом }\end{array}$ & $\begin{array}{c}\text { Бюджети- } \\
\text { рование, } \\
\text { основан- } \\
\text { ное на } \\
\text { расходах } \\
\text { предыду- } \\
\text { щего } \\
\text { периода }\end{array}$ & $\begin{array}{c}\text { Фор- } \\
\text { мульное } \\
\text { финанси- } \\
\text { рование }\end{array}$ & $\begin{array}{c}\text { Заключение } \\
\text { контрактов } \\
\text { о предостав- } \\
\text { лении услуг } \\
\text { в соответ- } \\
\text { ствии со } \\
\text { стратеги- } \\
\text { ческими } \\
\text { целями }\end{array}$ & $\begin{array}{c}\text { Контрак- } \\
\text { ты, содер- } \\
\text { жащие } \\
\text { целевые } \\
\text { показатели } \\
\text { выпуска } \\
\text { специа- } \\
\text { листов } \\
\text { различных } \\
\text { специаль- } \\
\text { ностей }\end{array}$ & $\begin{array}{c}\text { Целевое } \\
\text { финан- } \\
\text { сиро- } \\
\text { вание } \\
\text { специ- } \\
\text { фичес- } \\
\text { ких } \\
\text { проектов }\end{array}$ \\
\hline Австрия & & & + & + & & + \\
\hline Бельгия (нем.) & + & & + & & & + \\
\hline Бельгия (флам.) & & & + & + & & + \\
\hline Бельгия (фр.) & & & + & & & + \\
\hline Болгария & + & & + & & & + \\
\hline $\begin{array}{l}\text { Великобритания } \\
\text { (Англия, Уэльс, } \\
\text { Северная } \\
\text { Ирландия) } \\
\end{array}$ & & & + & & & + \\
\hline $\begin{array}{l}\text { Великобритания } \\
\text { (Шотландия) }\end{array}$ & & & + & & & + \\
\hline Венгрия & & & + & & & + \\
\hline Германия & \multicolumn{6}{|c|}{ Определяется региональными органами управления } \\
\hline Греция & + & + & + & + & & + \\
\hline Дания & & + & + & + & & + \\
\hline Ирландия & + & & + & & & + \\
\hline Исландия & & + & + & + & & + \\
\hline Испания & \multicolumn{6}{|c|}{ Определяется региональными органами управления } \\
\hline Италия & & + & + & & & + \\
\hline Кипр & + & & & & & \\
\hline Латвия & & & + & & + & + \\
\hline Литва & & & + & & & \\
\hline Лихтенштейн & & & + & & & + \\
\hline Люксембург & + & & & + & & $\ldots$ \\
\hline Мальта & + & & & & & + \\
\hline Нидерланды & & & + & & & + \\
\hline Норвегия & & + & + & & & + \\
\hline Польша & & + & + & & & + \\
\hline Португалия & + & & + & + & & + \\
\hline Румыния & & & + & + & & + \\
\hline Словакия & & & + & + & & + \\
\hline Словения & + & & + & & & + \\
\hline Финляндия & & & + & + & & + \\
\hline Франция & & & + & + & & + \\
\hline Чехия & & & + & + & & + \\
\hline Швеция & & & + & + & & + \\
\hline Эстония & & & + & & + & + \\
\hline
\end{tabular}

Примечание. Составлено авторами по Eurydice (2015). Higher Education Governance in Europe. Policies, structures, funding and academic staff. 
чественных параметрах деятельности вуза. Доля подобного финансирования в ряде стран достигает $100 \%$ от средств, которые выделяют вузам на обучение студентов (однако это не исключает дополнительного финансирования в виде целевого финансирования исследовательских проектов и программ).

При расчетах объема финансирования вуза используют коэффициенты, которые бы учитывали специальность, тип учебной программы или категорию вуза. Основное назначение таких коэффициентов - отражение соотношения стоимости обучения студентов на программах различных направлений высшего образования. К примеру обучение студента-инженера требует больших затрат, чем подготовка студента-гуманитария. Более того, в России существуют законодательно закрепленные нормы затрат на обучение студентов разных специальностей. Одним из последних законодательных актов, по которым работают вузы, является Приказ Минобрнауки России № 884 от 20.07.2016 «О значениях базовых нормативов затрат на оказание государственных услуг в сфере образования и науки, молодежной политики, опеки и попечительства несовершеннолетних граждан и значений отраслевых корректирующих коэффициентов к ним».

Часто весовые коэффициенты использует государство для осуществления контроля за структурой приема в вузы. Например, если правительство хочет увеличить количество специалистов определенной специальности, оно повышает подушевой норматив финансирования для соответствующих специальностей или типов программ.

Некоторые исследователи считают, что финансирование на основе учета результатов должно использоваться в качестве поощрения вуза за успешную работу, но не как способ влияния на высшее образование в стране в целом.

Современное российское финансирование вузов пошло по своему собственному пути. Ограниченность бюджетных средств, необходимость их грамотного распределения между участниками рынка образовательных услуг, разнообразие объектов высшей школы и жесткая конкуренция между ними как на российской, так и на зарубежной арене - все эти современные рыночные реалии поставили вопрос о необходимости изменения подходов к бюджетному финансированию высшей школы в России.

Самостоятельная, инициативная деятельность, которая осуществляется вузом от своего имени и под свой риск с целью систематического получения дохода - выводит современные высшие учебные заведения на новый уровень и присваивает им абсолютно новый статус предпринимательского вуза (ПВ).

Доходом или прибылью вуза в данном случае становится сумма финансирования из бюджета государства. Иначе говоря, на данный момент времени ПВ, как и обычные предприниматели на рынке, всячески демонстрирует свои управленческие качества и принимает решения в своей повседневной деятельности с целью повышения своей конкурентоспособности на рынке образовательных услуг и получения от государства как можно большего объема финансовых средств.

Показатели результативности деятельности вузов, рассмотренные выше, для простоты расчетов предлагается объединить в три обобщенные группы:

- показатель эффективности вуза в образовательной деятельности;

- показатель эффективности НИОКР вуза;

- показатель эффективности инновационной деятельности вуза.

Исследование проблем эффективности деятельности вузов и разработанные критерии оценки представлены в таблице 2 .

Для более ясной характеристики предлагаемой модели бюджетного финансирования предпринимательского вуза условно разделим показатели эффективности на три группы:

1) эффективность до $50 \%$ - своеобразная «группа риска»;

2) эффективность от 51 до $70 \%$ - своего рода «средний класс»;

3) эффективность от 71 до $100 \%$ - показатели, которыми обладают вузы-лидеры рынка.

Именно такое деление предлагается в связи с теми видами деятельности, которые показывают вузы. Ежегодно Министерство образования и науки проводит мониторинг деятельности вузов по целому списку показателей, начиная от количества обучающихся и заканчивая числом коммерциализованных НИОКР. 


\section{Определение эффективности работы вуза в соответствии с направлениями его деятельности}

\begin{tabular}{|c|c|c|c|}
\hline & Показатель & Формул а & Комментарии \\
\hline 1 & $\begin{array}{l}\text { Эффективность } \\
\text { вуза в } \\
\text { образовательной } \\
\text { деятельности }\end{array}$ & $\ni_{o}=\frac{Q_{y .8 .}}{Q_{n . \partial .}} \times 100 \%$ & $\begin{array}{l}\text { Qп.д. - общее количество } \\
\text { студентов, получивших диплом } \\
\text { конкретного вуза вне зависимости } \\
\text { от специализации его } \\
\text { трудоустройства } \\
\text { Qу.в. - количество студентов, } \\
\text { которые устроились на работу по } \\
\text { полученной специальности в } \\
\text { первый год после окончания } \\
\text { конкретного вуза }\end{array}$ \\
\hline 2 & $\begin{array}{l}\text { Эффективность } \\
\text { НИОКР вуза }\end{array}$ & $\ni_{\text {ниокР }}=\frac{Q_{n . н . u}}{Q_{n .8}} \times 100 \%$ & $\begin{array}{l}\text { Qп.в. - общее количество } \\
\text { науко емких проектов, } \\
\text { фундаментальных и прикладных } \\
\text { научных исследований, } \\
\text { выполненных за год работы вуза } \\
\text { Qп.н.и. - количество наукоемких } \\
\text { проектов, фундаментальных и } \\
\text { прикладных научных исследований, } \\
\text { которые нашли дальнейшее } \\
\text { использование на практике }\end{array}$ \\
\hline 3 & $\begin{array}{l}\text { Эффективность } \\
\text { инновационной } \\
\text { деятельности вуза }\end{array}$ & $\ni_{\text {u.d. }}=\frac{Q_{p . \kappa .}}{Q_{p .}} \times 100 \%$ & $\begin{array}{l}\text { Qp. - общее количество всех } \\
\text { инновационных результатов, } \\
\text { полученных вузом за год работы } \\
\text { Qр.к. - количество } \\
\text { коммерциализованных } \\
\text { инновационных результатов вуза }\end{array}$ \\
\hline
\end{tabular}

Примечание. Составлено авторами.

Вузы, относящиеся к группе риска, на протяжении нескольких периодов выдают плачевные результаты. Меньше половины их выпускников устраиваются по своей специальности. Что заставляет задуматься о целесообразности нахождения данного вуза на рынке образовательных услуг.

Вузы второй группы показывают средние результаты, больше половины их выпускников трудоустраиваются по специальности. Однако таким вузам необходимо непрерывно улучшать свою деятельность и сводить к минимуму недостатки.

Вузам-лидерам необходимо всего лишь ежегодно максимизировать свои показатели и не позволять им снижаться. Такой вуз достоин поощрения в виде дополнительных выплат от государства.

После определения эффективности деятельности вуза представляется возможным рассчитать итоговую сумму объема финансирования вузов:

$$
\sum_{\text {финансирования }}=\sum C_{\text {смета }}+\sum \Pi,
$$

где $\Sigma C_{\text {смета }}$ - бюджет, который вуз определяет самостоятельно, руководствуясь своими плановыми показателями, руб.; $i_{\text {эффективности }}$ процент эффективности, который вычисляется по формулам из таблицы 2; $\Sigma П$ - объем поощрения вуза за эффективность его деятельности, руб.

$$
\sum \Pi=\sum C_{\text {смета }} \times i_{\text {эффективности }} .
$$

Проведем анализ применимости данной формулы на практике по данным Самарского национального исследовательского университета им. академика С.П. Королева (см. табл. 3).

Рассчитаем показатели эффективности вуза в образовательной и инновационной деятельности, НИОКР.

Показатель эффективности вуза в образовательной деятельности:

$$
\ni_{\mathrm{o}}=\frac{2404}{2420} \times 100 \%=99,3 \%
$$




\section{Исходные данные для расчета показателей эффективности деятельности вуза}

\begin{tabular}{|c|l|c|}
\hline $\begin{array}{c}\text { № } \\
\text { п/п }\end{array}$ & \multicolumn{1}{|c|}{ Показатель } & 2015 г. \\
\hline 1 & $\begin{array}{l}\text { Общее количество студентов, получивших диплом университета вне } \\
\text { зависимости от специализации его трудоустройства, чел. }\end{array}$ & 2420 \\
\hline 2 & $\begin{array}{l}\text { Количество студентов, которые устроились на работу по полученной } \\
\text { специльности в первый год после окончания вуза, чел. }\end{array}$ & 2404 \\
\hline 3 & $\begin{array}{l}\text { Общее количество наукоемких проектов, фундаментальных и } \\
\text { прикладных научных исследований, выполненных за год работы вуза, шт. }\end{array}$ & 229 \\
\hline 4 & $\begin{array}{l}\text { Количество наукоемких проектов, фундаментальных и прикладных } \\
\text { научных исследований, которые нашли дальнейшее использование на } \\
\text { практике, шт. }\end{array}$ & $\begin{array}{l}\text { Общее количество всех инновационных результатов, полученных вузом } \\
\text { за год работы, млн руб. }\end{array}$ \\
\hline 5 & $\begin{array}{l}\text { Количество коммерциализованных инновационных результатов вуза, } \\
\text { млн руб. }\end{array}$ & 6,52 \\
\hline
\end{tabular}

Примечание. Составлено авторами по данным, полученным от отдела сопровождения научных исследований Самарского университета.

Показатель эффективности НИОКР вуза:

$$
Э_{\text {ниокр }}=\frac{229}{393} \times 100 \%=58,27 \% .
$$

Показатель эффективности инновационной деятельности вуза:

$$
Э_{\text {и.д. }}=\frac{6,52}{8,48} \times 100 \%=76,88 \% \text {. }
$$

Для определения группы эффективности вуза необходимо рассчитать его усредненный показатель эффективности:

$$
\begin{aligned}
& Э=\frac{Э_{о}+Э_{\text {н.д. }}+Э_{\text {ниокр }}}{3}= \\
& =\frac{99,3+58,27+76,88}{3}=78,15 \% .
\end{aligned}
$$

Как видно из полученных результатов эффективности образовательной деятельности, рассматриваемый вуз относится к третьей группе эффективности и является вузом-лидером рынка.

Сумма поощрения может варьироваться в зависимости от полученного вузом показателя эффективности (см. табл. 4).

Рассчитаем итоговую сумму объема финансирования на основании полученных данных по показателю эффективности образовательной деятельности, учитывая, что планируемый бюджет Самарского университета на 2017 г. составляет 2 435,642 млн руб.:

$$
\begin{gathered}
\sum_{\text {финансирования }}=2435,642++_{+} \\
+(2435,642 \times 40 \%)=3409,89 .
\end{gathered}
$$

Алгоритм предлагаемой модели финансирования выглядит следующим образом:

1. Когда показатель эффективности вуза станет равным $65 \%$, он начнет получать объем финансирования, равный запланированному бюджету на год.

2. При повышении эффективности на $1 \%$ объем финансирования увеличится на $1 \%$ (схема «1 к 1»).

3. Вузы со 100 \%-й эффективностью имеют возможность получать в качестве поощрения дополнительные $50 \%$ от бюджета.

4. Максимальные потери в финансировании могут понести вузы, относящиеся к «среднему классу» - 19 \% бюджета.

5. В случае если вуз повышает свой процент эффективности и переходит из одного класса в другой, то финансирование ведется по схеме « $1 \%+5 \%$, то есть дополнительно к $1 \%$ за увеличение эффективности он получает еще $5 \%$ за счет перехода в другой класс.

Однако с 2016 г., помимо показателей эффективности, на размер финансирования вузов влияет проходной балл ЕГЭ, что позволяет вузам привлекать более подготовленных и успешных абитуриентов, но не отменяет их обязанности повышать свою конкурентоспособность на рынке образовательных услуг.

В рамках современной экономической ситуации в России применение данной методики позволит существенно снизить государственные расходы на финансирование заведо- 
Зависимость объема поощрения вуза от его показателя эффективности

\begin{tabular}{|l|c|c|c|}
\hline $\begin{array}{c}\text { Классификация } \\
\text { вуза }\end{array}$ & $\begin{array}{c}\text { Полученный показатель } \\
\text { эффективности, \% }\end{array}$ & Класс & $\begin{array}{c}\text { Сумма поощрения (в \% от } \\
\text { запланированного бюджета) }\end{array}$ \\
\hline «Группа риска» & До 51 & - & - \\
\hline «Средний класс» & $51-60$ & 5 & 30 \\
\hline «Средний класс» & $61-70$ & 4 & 35 \\
\hline «Вузы-лидеры» & $71-80$ & 3 & 40 \\
\hline «Вузы-лидеры» & $81-90$ & 2 & 45 \\
\hline «Вузы-лидеры» & $91-100$ & 1 & 50 \\
\hline
\end{tabular}

Примечание. Составлено авторами.

мо неэффективных вузов (путем уменышения сумм причитающихся им субсидий и фактическим перераспределением средств более эффективным вузам), а также выплат пособий по безработице выпускникам с невостребованными специальностями. Ведь, как известно, в феврале 2017 г. вышло постановление о серьезном сокращении финансирования вузов, вошедших в государственную программу «5100». Так как данная программа подразумевает под собой выход российских университетов в международные рейтинги, то предлагаемая методика финансирования позволит еще больше стимулировать вузы к конкурентной борьбе и улучшению своей деятельности.

В российской практике следует, учитывая зарубежный опыт, использовать элементы финансирования, ориентированного на результаты, обеспечивая при этом действенный контроль за качеством образовательных услуг.

\section{СПИСОК ЛИТЕРАТУРЫ}

1. Белоусова, А. На финансирование вузов теперь будет влиять проходной балл ЕГЭ / А. Белоусова // Спутник FM. - 2015. - Электрон. текстовые дан. - Режим доступа: http://sputnik.fm/news/ 7365 na finansirovanie vuzov teper budet vlijat prokhodnoj_ball (дата обращения: 05.06.2017). Загл. с экрана.

2. Беляева, Д. Ю. Бюджетирование, ориентированное на результат и проблема идентификации «результата» / Д. Ю. Беляева // Финансовый вестник: финансы, налоги, страхование, бухгалтерский учет. - 2010. - № 2. - С. 34-39.

3. Беляков, С. А. Модели финансирования вузов: анализ и оценка / С. А. Беляков. - М. : Технопечать, 2005. - С. 151-161.

4. Галимов, А. М. Об оценке результатов инновационной деятельности вузов / А. М. Галимов, А. Р. Закирова, А. В. Маханько // Образова- тельные технологии и общество. - 2013. - Т. 16, № 4. - С. 403-411.

5. Кулакова, М. Н. К вопросу о бюджетном финансировании деятельности вуза: современный подход / М. Н. Кулакова // Территория новых возможностей. Вестник ВГУЭС. - 2012. - № 2. - С. 124-129.

6. Толочко, И. Г. Финансирование в сфере высшего образования: основные проблемы / И. Г. Толочко // Молодой ученый. - 2014. - № 19. - С. 371-374.

7. Хромов, А. М. Данные круглого стола на тему: «Эффективное образование» в «неэффективных вузах»: в чем провинились ведущие университеты страны?» / А. М. Хромов. - М., 2012. - Электрон. текстовые дан. - Режим доступа: http://www. iarex.ru/education/30980.html (дата обращения: 05.02.2016). - Загл. с экрана.

8. Ястребова, О. К. Использование показателей результатов при финансировании вузов: зарубежный опыт : информационно-аналитические материалы, подготовленные по проекту: «Разработка, апробация и внедрение инструментов программно-целевого бюджетного планирования и администрирования бюджетных расходов, ориентированных на результаты, в сфере образования» / О. К. Ястребова. - М., 2009.

\section{REFERENCES}

1. Belousova A. Na finansirovanie vuzov teper budet vliyat prokhodnoy ball EGE [The Financing of Universities will Now be Influenced by the Passing Score of the Unified State Examination]. Sputnik FM, 2015. URL: http://sputnik.fm/news/7365_na finansirovanie_vuzov teper_budet_vlijat prokhodnoj_ball. (accessed June 5, 2017).

2. Belyaeva D.Yu. Byudzhetirovanie, orientirovannoe na rezultat i problema identifikatsii «rezultata» [Performance-Based Budgeting, and the Problem of Identification of "Performance"]. Finansovyy vestnik: finansy, nalogi, strakhovanie, bukhgalterskiy uchet, 2010, no. 2, pp. 34-39.

3. Belyakov S.A. Modeli finansirovaniya vuzov: analiz $i$ otsenka [Models of Financing Higher 
В.В. Ковельский, К.А. Сидоренкова. Проблемы бюджетного финансирования высших учебных заведений

Education Institutions: Analysis and Evaluation], Moscow, Tekhnopechat Publ., 2005, pp. 151-161.

4. Galimov A.M., Zakirova A.R., Makhanko A.V. $\mathrm{Ob}$ otsenke rezultatov innovatsionnoy deyatelnosti vuzov [On the Evaluation of the Results of Innovation Activities of Universities]. Obrazovatelnye tekhnologii i obshchestvo, 2013, vol. 16, no. 4, pp. 403-411.

5. Kulakova M.N. K voprosu o byudzhetnom finansirovanii deyatelnosti vuza: sovremennyy podkhod [On the Budget Financing of the University: Modern Approach]. Territoriya novykh vozmozhnostey. Vestnik VGUES, 2012, no. 2, pp. 124-129.

6. Tolochko I.G. Finansirovanie v sfere vysshego obrazovaniya: osnovnye problemy [Financing in Higher Education: the Main Problems]. Molodoy uchenyy, 2012, no. 19, pp. 371-374.

7. Khromov A.M. Dannye kruglogo stola na temu: «Effektivnoe obrazovanie»v «neeffektivnykh vuzakh»: v chem provinilis vedushchie universitety strany?» [Data from the Round Table on the Topic:
"Effective Education" in "Inefficient Universities": What's the Guilt of the Leading Universities in the Country?']. Moscow, 2012. URL: http://www.iarex.ru/ education/30980.html. (accessed February 5, 2016).

8. Yastrebova O.K. Ispolzovanie pokazateley rezultatov pri finansirovanii vuzov: zarubezhnyy opyt: informatsionno-analiticheskie materialy, podgotovlennye po proektu: "Razrabotka, aprobatsiya $i$ vnedrenie instrumentov programmnotselevogo byudzhetnogo planirovaniya $i$ administrirovaniya byudzhetnykh raskhodov, orientirovannykh na rezultaty, v sfere obrazovaniya» [The Use of Performance Indicators in the Financing of Universities: Foreign Experience. Information and Analytical Materials Prepared for the Project "Development, Approbation and Implementation of Tools for Program-Targeted Budgetary Planning and Administration of Persormance-Oriented Budgetary Expenditure, in the Field of Education"]. Moscow, 2009.

\section{Information About the Authors}

Viktor V. Kovelskiy, Candidate of Sciences (Economics), Associate Professor, HR Global Manager, Samara National Research University named after S.P. Korolev, Moskovskoe Highway, 34a, 443086 Samara, Russian Federation, kovelskiy@mail.ru.

Kseniya A. Sidorenkova, Master Student, Specialist of Human Resourses Department, Samara National Research University named after S.P. Korolev, Moskovskoe Highway, 34a, 443086 Samara, Russian Federation, ks@ssau.ru.

\section{Информация об авторах}

Виктор Владиславович Ковельский, кандидат экономических наук, доцент, начальник управления по работе с персоналом, Самарский национальный исследовательский университет им. С.П. Королева, Московское шоссе, 34a, 443086 г. Самара, Российская Федерация, kovelskiy@mail.ru.

Ксения Алексеевна Сидоренкова, магистрант, специалист отдела подбора и развития персонала управления по работе с персоналом, Самарский национальный исследовательский университет им. С.П. Королева, Московское шоссе, 34a, 443086 г. Самара, Российская Федерация, ks@ssau.ru. 